\title{
CORRESPONDENCE
}

Continued use of hormonal pregnancy tests

C L Brewer, MRCPSYCH.............

Teratogenic effects of waste anaesthetic gases

$\mathrm{K}$ McPherson, PHD, and others; D I

Rushton, MRCPATH ; P J Tomlin, FFARCS. . . 437

Maternal pethidine and neonatal

depression

M Rosen, FFARCs, and others.........438

Regional variations in the incidence of urinary stones

R Scott, FRCSGLAS; S Ljunghall, MD..... 439

Help for parents after stillbirth

E Lewis, FRCPSYCH ; D Morris, FRCP . . . . . 439

Fluids for parenteral nutrition

R C Smith, Fracs, and others......... 440

Noxythiolin-resistant organisms

B Chattopadhyay, MRCPATH.........440 440

Psychological evaluation in cases of selfpoisoning

A Munro, MD; R Gardner, MRCPSYCH

and others...................440 440

Delayed respiratory depression after use

of fentanyl

C J Wright, FFaRcs; J H Williams, FFarcs. . 441
The water story

A Michell, PHD; G H B Martin, MD..... 441

Aistosomiasis, metriphonate,

cholinesterase, and suxamethonium

$M$ F M James, FFARCs, and J M Jewsbury,

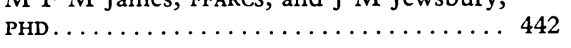

Paracetamol overdosage

W D Toff................. 442

Confidentiality and life insurance

T M Pickard, MB............... 442

Breast lumps in adolescent girls

Agnes M Stark, MD; D McCracken, FRCP.. 443

Carcinoma in a gastroenterostomy stoma

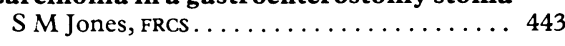

Yawning in pharyngeal obstruction

Elizabeth B Evans, MB............ 443

Epilepsy in Paget's disease of the skull

G B Tait, FRCPED................ 444

Thyroid disease and asthma

H G J Herxheimer, LRCP. . . . . . . . . 444

Golfers' wrist

J S Blackburne, FRCS . . . . . . . . . . . 444

An international nomenclature of diseases $\mathrm{Z}$ Bankowski, MD, and A H T Robb-Smith,

FRCP.................... 444
Shadow over Maltese medicine

P C Arnold, MB . . . . . . . . . . . 444

Malta appeal

E J King, мв . . . . . . . . . . . . . . 444

Wasted women doctors

A Holzel, FRCP, and D H Vaughan, MFCM. . 444

Training and careers of women doctors

D A Jennings, BM; Berenice $R$ Beaumont,

MB . . . . . . . . . . . . . . . . . . 444

Redundant doctors

H H Langston, FRCS . . . . . . . . . . 445

General practitioner paediatrician

G D Starte, FRCGP . . . . . . . . . . . . . . 445

New consultant contract

D L Froggatt, FRCS; J Lowther, MRCPSYCH 445 Registration of overseas doctors

C S Ward, fFARCS ................ 446

The Ombudsman and the patient's notes

J K Brennand, FRCS. . . . . . . . . . . . . . 446

Points from letters: Vitamin $\mathrm{E}$ in treatment of Huntington's chorea (Margery Hall); Unusual complication of barium enema (A Cohen); Help for parents after stillbirth (Jean J Proud and $\mathrm{H}$ Banbury); Aerosol inhaler technique (D Davies); Of molluscs and men (W S Killpack); A British "Doctors' Ten"? (E I R Taylor) Phase 2 pay award (J W S Rickett)......446
Correspondents are urged to write briefly so that readers may be offered as wide a selection of letters as possible. So many are being received that the omission of some is inevitable. Letters must be signed personally by all their authors.

\section{Continued use of hormonal pregnancy tests}

SIR,-Hormonal pregnancy tests (HPTs) were very widely used until the mid-1960s, when a general post-thalidomide reluctance to give drugs during pregnancy coupled with the development of simple immunological tests led to their gradual abandonment. In 1975 this trend was given official approval when the Committee on Safety of Medicines (CSM) issued a warning based on a preliminary report of an association between HPTs and subsequent congenital abnormalities. The committee said then that HPTs should not be used.

Following a further report which confirmed the association, ${ }^{2}$ the CSM issued a second warning in November 1977 and stated again that "hormonal tests for pregnancy should not be used. Alternative methods are available which are free from this risk." This warning received considerable publicity in the lay as well as the medical press and questions were asked in Parliament, where the Secretary of State declined to ban the proprietary drug concerned. ${ }^{3}$

Informal inquiries among colleagues indicated that HPTs were still being prescribed and I conducted a small survey to discover the extent of their use. During December 1977 and January 1978-that is, shortly after the latest CSM warning-600 consecutive patients requesting abortion were asked whether they had been given HPTs since the discovery of their latest pregnancy. Twelve patients $(2 \%)$ had received such tests. Six separate branches of the British Pregnancy Advisory Service took part in this survey and all reported at least one HPT per 100 patients, so that this finding is unlikely to reflect either chance or the presence of a particularly recalcitrant general practitioner in just one area.

The figure of $2 \%$ is almost certainly an underestimate of the actual use, because only a minority of the women had consulted a GP before coming to BPAS, so that most of them were not at risk. Although in some cases the GPs may have prescribed HPT in the belief that the pregnancy would be terminated and that teratological risks could therefore be ignored, some of the HPTs were prescribed by GPs who subsequently refused to refer the woman for abortion. In any case, a significant proportion of women change their minds about abortion and decide to go to term. No doubt some women ask for "something to bring on a period," but oestrogens are effective as abortifacients only within a day or two of conception and GPs are deluding themselves as well as their patients if they believe otherwise.

This study has revealed an area of persisten malpractice which represents an easily avoidable hazard. If banning the drug in question -Primodos-is thought an unacceptable infringement of professional freedom, perhaps the Department of Health and Social Security will consider making it a controlled drug with a requirement that before prescribing it the doctor must satisfy himself by an immunological test that the recipient is not pregnant.

COLIN BREWER

British Pregnancy Advisory Service,

Solihull,

W Midlands

${ }^{1}$ Greenberg, G, et al, British Medical fournal, 1975, 2, 191.
2, 853.

Hansard, House of Commons, 21 November 1977, cols 465-467.

Teratogenic effects of waste anaesthetic gases

SIR,-Knill-Jones et $a l^{1}$ found no evidence of an excess of major congenital malformations among the 5175 offspring of British male anaesthetists. It would therefore be wise to interpret with caution Dr P J Tomlin's (14 January, $p$ 108) finding of four children with congenital abnormalities and one with an ependymoma among 135 offspring of 75 Birmingham anaesthetists. If we assume that major congenital defects occur in about $1 \%$ of all births, ${ }^{1}$ the probability of observing by chance four malformed children in a sample of 135 is about 0.05 . This is not a rare occurrence. If, for example, we were to divide Britain up into areas each containing about 75 anaesthetists we would expect, by chance alone, a situation as extreme as or more extreme than that observed by Dr Tomlin to exist in $5 \%$ of them. Furthermore, studies of small series in which no odd effects are seen are neither likely to be submitted to journals nor published if submitted, so that the conventional method of assigning a $P$ value to 
such reports as are published almost certainly underestimates the true probability, as the selective reporting and publishing bias is not taken into account.

It is certainly both wrong and misleading to present the probability ("less than one in a million") of obtaining specific kinds of unrelated abnormality (ependymoma, aqueduct stenosis, and kyphoscoliosis) after they have been observed when there was no prior hypothesis that such abnormalities would be seen. If the successive outcomes of tossing a coin 20 times are recorded the probability of obtaining the specific sequence observed is also less than one in a million; however, this does not necessarily allow us to infer that there is anything unusual about the coin.

That the five abnormal births in Birmingham were all female adds little weight to D Tomlin's findings, as there is a not unusually low probability ( 1 in 16) that five such birth will involve children of the same sex by chance alone.

Finally, Dr Tomlin's statement that "since the only feature that is common to all the affected children was that the father was an anaesthetist this implies that there is an occu pational hazard" is an extraordinary one. Since Dr Tomlin's study was limited to children born to anaesthetists it is hard to see how a different result could have been achieved.

KLIM MCPHERSON

Peter SMith

MARTIN VesSEY

Department of Social and
Community Medicine,
University of Oxford

Knill-Jones, R P, et al, Lancet, 1975, 2, 807.

SIR,-Sir Derrick Dunlop ${ }^{1}$ commented that "the majority of our opinions are mere wish fulfilments, like dreams in Freudian theory, and the mind of the most rational can be compared to a stormy ocean of passionate conviction based upon desire, upon which floats perilously a few tiny boats carrying their cargo of scientifically vested beliefs." Dr P J Tomlin is a well-known crusader for the reduction of pollution in operating theatres, but I would suggest that his most recent evidence and conclusions (14 January, p 108) can only bring his cause into disrepute. The minute "cargo" on which Dr Tomlin's arguments are based would seem to have little scientific vestment. It is therefore all the more unfortunate that the local press and media appear to have accepted his views at their face value.

The assembly of a miscellaneous assortment of disorders identified in families in which the father is an anaesthetist, including an acquired lesion (hydrocephalus subsequent to meningitis), a tumour, and a possible degenerative or metabolic disorder (case 5 in the table), under the title of congenital deformities is not only terminologically incorrect but is also clearly misleading. I am not a statistician, but I doubt that the method of collection of the data and the arguments which follow are valid. Furthermore, it would seem remarkable that the only feature the five children had in common was their fathers' occupation, particularly as this was their reason for inclusion in the report.

If the irrelevant and equivocal disorders are excluded there are two cases of congenital dislocation of the hip (one associated with scoliosis), one of talipes (which may be related to the central nervous system disorder), and ne of hydrocephalus. All these malformations, with the possible exception of the last, are classified among the commoner abnormalities $^{2}$; thus the absence of cleft palate and congenital heart disease in a series of four cannot be considered remarkable. Furthermore, four cases of differing anomalies can hardly be said to demonstrate a "pattern" of malformations either on statistical or embryological criteria.

I have criticised the data on abortion elsewhere $^{3}$ and I do not find that official recognition in any way influences my views. Abortions alone, ${ }^{4}$ let alone abortions and underweight fetuses, do not form a homogeneous population on either morphological or aetiological criteria

While there may be an argument for reducing theatre pollution on general environmental principles, the case against anaesthetic gases remains far from proved. The presentation of terminologically inaccurate data of, at the best, equivocal statistical significance can do little to enhance it, though it clearly attracted the attention of the media. The acceptance of malformations in children of exposed theatre staff as an "industrial" disease, which appears to be what Dr Tomlin is advocating when he asks the Department of Health and Social Security to accept responsibility for the affected offspring, would, on present evidence, seem to be opening the floodgates of teratological litigation far beyond the confines of the Health Service.

D I RUSHTON

Birmingham Maternity Hospital,

Birmingham

'Doll, R, Fournal of the Irish Medical Association, 1973, 66, 117 .

Polani, P E, Guy's Hospital Reports, 1973, 122, 53.

Rushon, D I, Touret,

***We sent copies of these two letters to $\mathrm{Dr}$ Tomlin, whose reply is printed below. $\mathrm{ED}, B M \mathcal{F}$.

SIR,-The purpose of my letter expressing concern about the teratogenic effects of waste anaesthetic gases was to give an example of what information could be obtained on inquiry in one city in which the inquirer knows the local situation and the people involved, so as to encourage others to do the same. Surveys such as the Knill-Jones ${ }^{1}$ survey do suffer from the problem of incomplete returns plus the resentment of the intrusion into the personal privacy of any affected family of an anonymous inquirer who requests a form of some sort to be completed. Since the defects observed were not the type to be observed at birth necessarily, inquiries into birth defects in the perinatal period, or thought to be confined to the perinatal period by those completing the survey, will inevitably lead to bias against any positive finding.

Dr Rushton and Dr McPherson and his colleagues appear to discount the case of ependymoma occurring in a child as being of congenital origin. In this they are in disagreement with experts in that field, but this assumption has coloured all their subsequent calculations.

The assumption by $\mathrm{Dr} \mathrm{McPherson}$ and his colleagues that major congenital abnormalities occur in $1 \%$ of all births is a generous one and includes all types of major abnormality. A better appraisal would have been to give the percentage probability of observing by chance a major defect in the central nervous or neuromuscular system in an apparently random sample of 135 children. I do not understand their statistical reasoning that the probability of a sequence of five female births is 1 in 16 . The probability of a female birth is very nearly $1 / 2$, for two females it is $1 / 2^{2}$, the alternative combinations being $M F, F M$, and $M M$, and for five females it is $1 / 2^{5}$ or 1 in 32 . Their remark that it is hard to see how a different result could have been achieved is naive-if all the children had been born in Birmingham it would be very easy to postulate a local environmental factor, but they were not; if there had been any common infection (an analogy is rubella) it would be very easy to postulate this, but there was no such infection.

Dr Rushton's letter raises two important moral arguments which I hope will not become widespread. These are (a) that one should not publish one's views in case they are socially inconvenient or disturbing medicolegally or otherwise; and $(b)$ that if one finds an unusual set of circumstances which are similar to other reports in humans and similar to congenital abnormalities induced by anaesthetic agents in experimental animals one should take no action until all the scientific niceties of statistical exactitude have been satisfied, and never mind how many children suffer in the process of achieving this exactitude. One of the important aspects of the thalidomide disaster was that early warnings indicating a potentially dangerous situation were ignored in the interest of statistical exactitude until the evidence was overwhelming, and today many children bear the scars of that particular argument.

The protagonists for the no-action camp must prove beyond all reasonable doubt that constant breathing of anaesthetic waste gases is totally harmless. This they have signally failed to do. It is important that young children should not be put at risk just to suit their ivory-towered intellectual purity, for if they are wrong the price in terms of human suffering is a very heavy one.

Peter J Tomlin

\section{University Department of Anaesthetics,} Queen Elizabeth Hospital, Birmingham

\section{Maternal pethidine and neonatal} depression

SIR,-Dr P W Barritt and others (14 January, p 106) criticise our trial (23 July, p 229) because we did not compare naloxone with nalorphine or levallorphan as well as with placebo. However, we had already shown in adult volunteers ${ }^{12}$ that levallorphan $1 \mathrm{mg}$ intravenously caused as much respiratory depression as morphine $20 \mathrm{mg}$ intravenously. (Nalorphine is even more depressant.) We were hardly likely therefore to include such drugs in a trial in neonates. Besides, neither nalorphine nor levallorphan had been used in our obstetric units for years. We cannot therefore accept their view that a comparison should now be made between naloxone and the older antagonists. If they are still unconvinced, let one of them personally try a dose of either drug. We have done so!

A previous study ${ }^{3}$ from this department had shown that naloxone $40 \mu \mathrm{g}$ intravenously reversed respiratory depression for up to 30 min. Subsequently we extended the period of observation to $48 \mathrm{~h}$ and demonstrated that at 